Journal of Thermal Engineering, Vol. 5, No. 4, pp. 277-292, July, 2019

Yildiz Technical University Press, Istanbul, Turkey

\title{
STATISTICAL ANALYSIS OF WIND SPEED DISTRIBUTION WITH SINOP- TURKEY APPLICATION
}

\author{
N. Balpetek ${ }^{1}$, E. Kavak Akpinar ${ }^{1, *}$
}

\begin{abstract}
In this study, the wind energy potential of the Sinop region was analyzed statistically by using the Turkish State Meteorological Station's hourly wind speed data between the years of 2005-2014. The two- parameter Weibull and one-parameter Rayleigh probability distribution functions were used to determine the wind energy potential of the region. The probability distribution functions were derived from the cumulative function and used to calculate the mean wind speed and the variance of the actual data. The best way of representing the performance of the Weibull and Rayleigh distributions is to use the statistical parameters such as the correlation coefficient $\left(\mathrm{R}^{2}\right)$, chi-square $\left(\chi^{2}\right)$ and the root mean square error analysis (RMSE). The results of the study showed that Sinop has a mean wind speed of $3.36 \mathrm{~m} / \mathrm{s}$ with a maximum value of $4.28 \mathrm{~m} / \mathrm{s}$ in February of 2011, and a minimum value of $2.41 \mathrm{~m} / \mathrm{s}$ in March of 2013, while the corresponding mean wind power density is approximately $33.31 \mathrm{~W} / \mathrm{m}^{2}$ for the whole year. In general, it was determined the wind speed is higher during some winter and spring months, notably February and March, and is lower during the autumn months. The Weibull distribution function was found to be more appropriate than the Rayleigh distribution function.
\end{abstract}

Keywords: Wind Energy, Statistical Analysis of Wind Energy Potential, Weibull Distribution, Rayleigh Distribution, Sinop-Turkey

\section{INTRODUCTION}

Renewable energy technologies play a strategic role in achieving the goals of sustainable economical development and environmental protection. Wind energy is one of the most important energy sources used widely as an alternative source [1].

In wind energy studies, statistical properties of the wind speed provides remarkable information to researchers and designers for predicting the output energy of a wind energy conversion system. Wind speed at a site varies randomly and its variation in a certain region over a period of time can be represented by different probability distribution functions (PDFs). Two-parameter Weibull distribution is the most commonly used and accepted distribution as it is found to be a fairly accurate PDF for most of the wind regimes found in nature and also it is simple to use. However, it is not suitable for certain wind regimes, such as those having high frequencies of null winds and for short time horizons. Another distribution Rayleigh PDF has also been used in many applications, owing to its simplicity and ability of describing wind speed with sufficient accuracy when little detail is available about the wind characteristics of a site [2].

Statistical distributions have been analyzed in the literature for examining differences between the results for day and night, between various seasons, and for monthly and yearly data. The suitability of these distribution functions for a particular application depends upon a number of factors such as the type of wind regime, availability of data, and recording intervals Moreover, a number of methods for estimating the parameters of these distributions and model evaluation criteria are given in the literature [2-5]. In recent years, many studies have been conducted to evaluate wind energy potential in different regions of Turkey by using various probability distribution functions and the results have shown that the Weibull and Rayleigh distributions can describe wind speed probability distribution well [6-21]. Ulgen and Hepbasli [6] determined the Weibull density distribution function to be able to predict the energy output of wind energy systems for Izmir- Turkey. Celik [7] analyzed the acceptability of the Weibull and Rayleigh distributions for modeling local wind profiles based on 1-year measured hourly time-series wind speed data

This paper was recommended for publication in revised form by Regional Editor Tolga Taner

${ }^{1}$ Department of Mechanical Engineering, Firat University, Elazig, Turkey

${ }^{\star}$ E-mail address: ebruakpinar@firat.edu.tr

Orcid id: 0000-0003-0666-9189

Manuscript Received 06 December 2017, Accepted 05 February 2018 
in the Iskenderun region of Hatay in Turkey. Karsli and Gecit [8] investigated the wind power potential of Nurdag1Gaziantep in the southern of Turkey. Kose et al. [9] evaluated the wind energy potential in Kutahya-Turkey according to wind data from a wind observation station established at the Dumlupinar University Campus. Akpinar and Akpinar [10-11] carried out studies using Weibull density function to demonstrate wind energy potential of Maden-Elazıg [10] and Agın-Elazı ğ [11] in eastern of Turkey. Genc et al. [12] estimated wind power potential in Aksehir-Turkey using the Weibull wind speed distribution function. Akpinar [13] investigated wind energy potential with respect to wind speed data from four stations, which are located in Elazig and its close regions. In their study, wind data were fitted to the Weibull and Rayleigh probability distribution functions and compared with each other. Gokcek et al. [14] investigated wind power potential in Kırklareli-Turkey using Weibull and Rayleigh functions for the year 2004. Yilmaz and Celik [15] determined appropriate theoretical pdf distribution by comparing $10 \mathrm{pdf}$ distributions (Beta, Erlang, Exponential, Gamma, Log-Logistic, Lognormal, Pearson V, Pearson VI, Uniform and Weibull) for the wind speed data measured in Gelibolu region. At the end of the comparison, Weibull was determined to be the best distribution representing wind data. Akdag and Güler [16] analyzed wind energy potential of Çanakkale region using Weibull distribution and real time series analysis, making use of hourly average wind data of the Turkish State Meteorological Service (TSMS) measured in $10 \mathrm{~m}$ height between 2001 and 2006. Bilgili and Sahin [17] investigated wind energy density in the southern and southwestern region of Turkey by using the Weibull and Rayleigh probability density functions. Mert and Karakus [18] determined the wind energy potential in Antakya through the use of a variety of statistical distributions, including the Burr, generalized gamma, and Weibull distributions. Dokur and Kurban [19] modelled wind energy potential based on two parameter Weibull distribution statistically for Bilecik, city in Turkey, by using the Turkish State Meteorological Service's hourly wind speed data between 2010 and 2014 measured. Kaplan and Aladag [20] analyzed statistically the wind energy potential in Hatay based on the data regarding the wind speed measured hourly between 2009 and 2013. Yanıktepe et al. [21] studied the wind energy potential of Osmaniye-Turkey using the Weibull and the Rayleigh models.

Wind data analysis and accurate wind energy potential assessment is critical for proper and efficient development of wind power application and is highly site-dependent. As a result, knowledge of the statistical properties of wind speed is essential for predicting the energy output of wind energy conversion system (WECS). Turkey has important wind energy potential especially in the coasts of western, southern and northern. The aim of this study is to investigate the wind energy potential of the Sinop province on Turkey's northern coast by using the wind data recorded at the Sinop Meteorological Station. An investigation of wind energy potential as a result of the distribution of wind speed in the Sinop province will draw attention to future wind energy projects.

\section{THEORY}

\section{Wind speed data}

The wind data used in this study were measured and recorded hourly at the Sinop station of the Turkish State Meteorological Service at $10 \mathrm{~m}$ above ground level between 2005 and 2014. The Sinop station (North Turkey), located in Mediterranean region (Figure 1) [22], is located at $42^{\circ} 01^{\prime} \mathrm{N}-35^{\circ} 11^{\prime} \mathrm{E}$, and its elevation is $32 \mathrm{~m}$ above sea level. The wind data were captured using a cup generator anemometer.

\section{Theory of wind speed and wind power}

The two-parameter Weibull distribution is the most widely used distribution in wind power applications. It is a versatile PDF, is simple to use, and is found to be accurate for most of the wind regimes encountered in nature. Rayleigh distribution is a special case of Weibull distribution in which the shape parameter is taken as $k=2$. This function has also been used by many researchers due to its simplicity as there is only one parameter to be evaluated and is useful when not much information about the site is available [2]. 


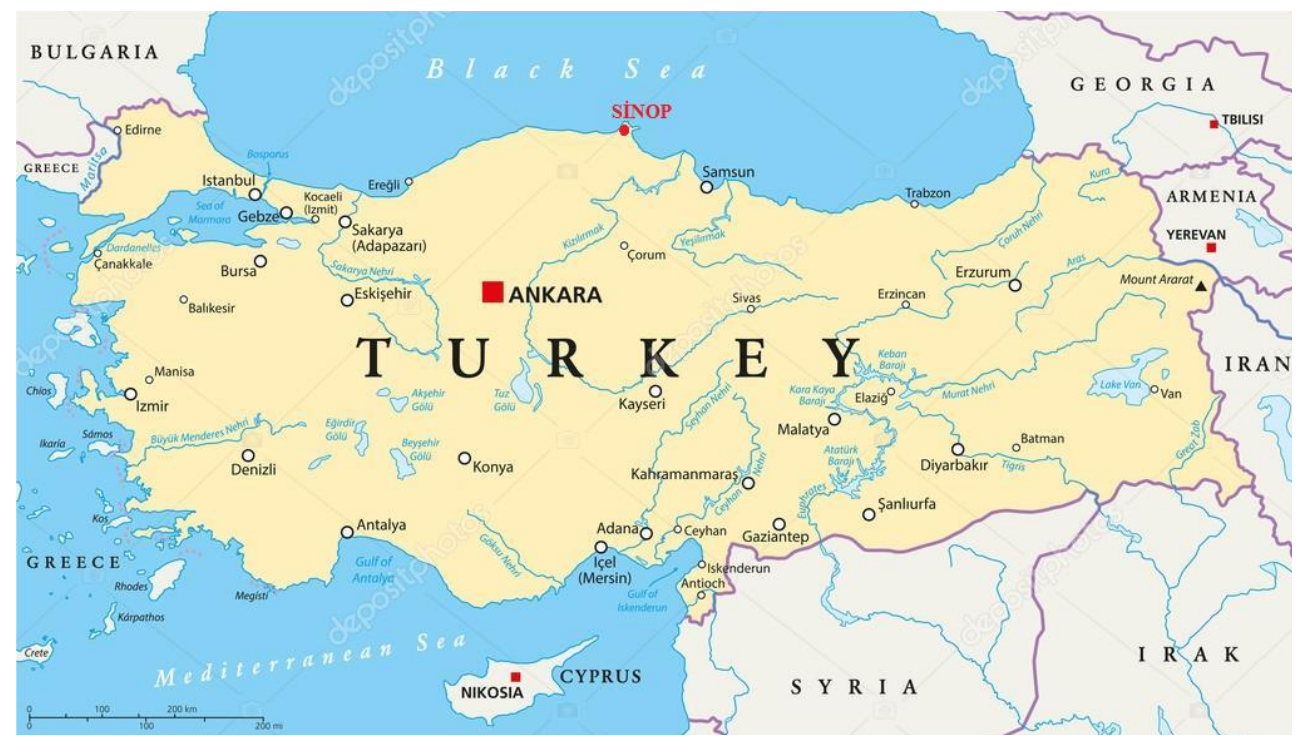

Figure 1. Location of Sinop on Turkey Map [22]

\section{Weibull and Rayleigh distribution of wind speed}

The monthly mean wind speed values and the standard deviations are calculated from Equepments. (1) and (2) using measured data.

$$
\begin{gathered}
v_{m}=\frac{1}{N}\left[\sum_{i=1}^{N} v_{i}\right] \\
\sigma=\left[\frac{1}{N-1} \sum_{i=1}^{N}\left(v_{i}-v_{m}\right)^{2}\right]^{1 / 2}
\end{gathered}
$$

The Weibull distribution function that is a special case of generalized gamma distribution for wind speed is expressed with Eq. (1).

$$
f_{w}(v)=\left(\frac{k}{c}\right)\left(\frac{v}{c}\right)^{k-1} \exp \left(-\left(\frac{v}{c}\right)^{k}\right)
$$

where $f_{w}(v)$ is the probability of observing wind speed $v, k$ the dimensionless Weibull shape parameter (or factor) and $c$ the Weibull scale parameter, which has its reference value in the units of wind speed [6, 10-14].

The cumulative probability function of the Weibull distribution is calculated as below [6, 10-14]:

$$
F_{w}(v)=1-\exp \left[-\left(\frac{v}{c}\right)^{k}\right]
$$

Determination of the parameters of the Weibull distribution requires a good fit of Eq. (4) to the recorded discrete cumulative frequency distribution. Taking the natural logarithm of both sides of Eq. (4) twice, gives 


$$
\ln \{-\ln [1-F(v)]\}=k \ln (v)-k \ln c
$$

So, a plot of $\ln \{-\ln [1-F(v)]\}$ versus $\ln v$ presents a straight line. The gradient of the line is $k$ and the intercept with the $y$-axis is $-k \ln c[6,10-11]$.

The $k$ values range from 1.5 to 3.0 for most wind conditions. Another distribution function used in determination of the wind speed potential is Rayleigh distribution. This distribution is a special case of Weibull distribution and validate situation where the dimensionless shape parameter $k$ of the Weibull distribution is assumed to be equal to 2. Probability density and cumulative function of the Rayleigh distribution are given by Eqs. (6) and (7), respectively [10-11],

$$
\begin{gathered}
f_{R}(v)=\frac{2 v}{c^{2}} \exp \left[-\left(\frac{v}{c}\right)^{2}\right] \\
F_{R}(v)=1-\exp \left[-\left(\frac{v}{c}\right)^{2}\right]
\end{gathered}
$$

The mean value of wind speed and its standard deviation may be computed using Eqs. (8) and (9), respectively,

$$
\begin{gathered}
v_{m}=c \Gamma\left(1+\frac{1}{k}\right) \\
\sigma=\sqrt{c^{2}\left\{\Gamma\left(1+\frac{2}{k}\right)-\left[\Gamma\left(1+\frac{1}{k}\right)\right]^{2}\right\}}
\end{gathered}
$$

where $\Gamma()$ is the gamma function [10-12].

Based on the Weibull distribution, the wind speed with the largest frequency is calculated from Eq. (10) [12]:

$$
V_{\bmod }=c\left(1-\frac{1}{k}\right)^{1 / k}
$$

The maximum wind speed can be determined by $[12,15]$ :

$$
V_{\max E}=c\left(\frac{k+2}{k}\right)^{1 / k}
$$

When $k=2$ is taken in the above formulas, calculations are performed for Rayleigh distribution.

\section{Calculations of wind power}

The wind power per unit area in any windy site is of importance in assessing of the wind power projection for the power plants. The mean wind power density of the considered site per unit area based on any probability density function can be expressed as [16]: 


$$
P_{m}=\int_{0}^{\infty} P(v) f(v) d v
$$

It is well known that the power of the wind that flows at speed $v$ through a blade sweep area $A$ increases as the cubic of its velocity and is given by,

$$
P(v)=\frac{1}{2} \rho A v^{3}
$$

Where $\rho$ is the air density for Sinop. The mean power density for the Weibull distribution is obtained from Eq. (14) as follows [7]

$$
P_{w}=\frac{1}{2} \rho c^{3} \Gamma\left(1+\frac{3}{k}\right)
$$

The mean power density for the Rayleigh distribution is determined by Eq. (15) [7]:

$$
P_{R}=\frac{3}{k} \rho v^{3} m
$$

\section{Statistical analysis of distributions}

Modeling efficiency $\left(\mathrm{R}^{2}\right)$, chi-square $\left(x^{2}\right)$ and root mean square error analysis (RMSE) and were used as the primary criterion to select the best distribution to account for the variation in the wind speed curves. Chi-square is the mean square of the deviations between the experimental and calculated values for the distributions and was used to determine the goodness of the fit. The lower are the values of chi-square, the better is the goodness of the fit. The RMSE gives the deviation between the predicted and experimental values, and it is required to approach zero. The $\mathrm{R}^{2}$ also gives the ability of the model, and its highest value is 1 . These statistical values can be calculated as follows:

$$
\begin{gathered}
R^{2}=\frac{\sum_{i=l}^{N}(y i-z i)^{2}-\sum_{i=l}^{N}(x i-y i)^{2}}{\sum_{i=l}^{N}(y i-z i)^{2}} \\
x^{2}=\frac{\sum_{i=l}^{N}(y i-x i)^{2}}{N-n} \\
R M S E=\left[\frac{1}{N} \sum_{i=l}^{N}(y i-x i)^{2}\right]^{1 / 2}
\end{gathered}
$$

where $y i$ is the $i t h$ experimental data, $z i$ is the mean value of the experimental data, $x i$ is the ith predicted data with the Weibull or Rayleigh distribution, $N$ is the number of observations and $n$ is the number of constants $[10,11,-13]$. 


\section{RESULTS AND DISCUSSION}

The measured hourly wind data between the years of 2004-2015 have been used to evaluate the wind energy potential of the Sinop province. The calculations were made to obtain the Weibull and Rayleigh distribution parameters, the mean power density and the mean wind speed. The main results obtained from the present study can be summarized as follows:

The monthly mean wind speed variations in Sinop are illustrated in Figure 2. It is also clear from Figure 2 that the wind speed for the investigated years had the lowest value in March of 2013 and the highest in February of 2011 , ranging from 2.41 to $4.28 \mathrm{~m} / \mathrm{s}$. The annual mean value of the wind speed was calculated as $3.36 \mathrm{~m} / \mathrm{s}$.

In Figure 3, the diurnal variation of the mean wind speed is plotted. According to the yearly average results, the lowest wind speed was $2.15 \mathrm{~m} / \mathrm{s}$ between the hours of 05:00 and 06:00 in 2006, and the highest wind speed was $3.89 \mathrm{~m} / \mathrm{s}$ between the hours of 13:00 and 14:00 in 2007. There is a similar trend in the mean wind speed of different daily hours during different years. The diurnal wind speed has its minimum between the hours of 0:00 and 18:00 and its maximum between the hours of 6:00 and 16:00. Figure 3 clearly shows that daily variations in wind speed from morning to midnight in Sinop follows a parabolic curve, where the maximum point occurs in the afternoon. In most locations around the world, the wind is more turbulent and conditions become windier during the daytime relative to the night time, mostly due to temperature differences. Therefore, the aforementioned situation is advantageous because the wind energy is mostly produced during the daytime, since the most electricity consumption is at night time.

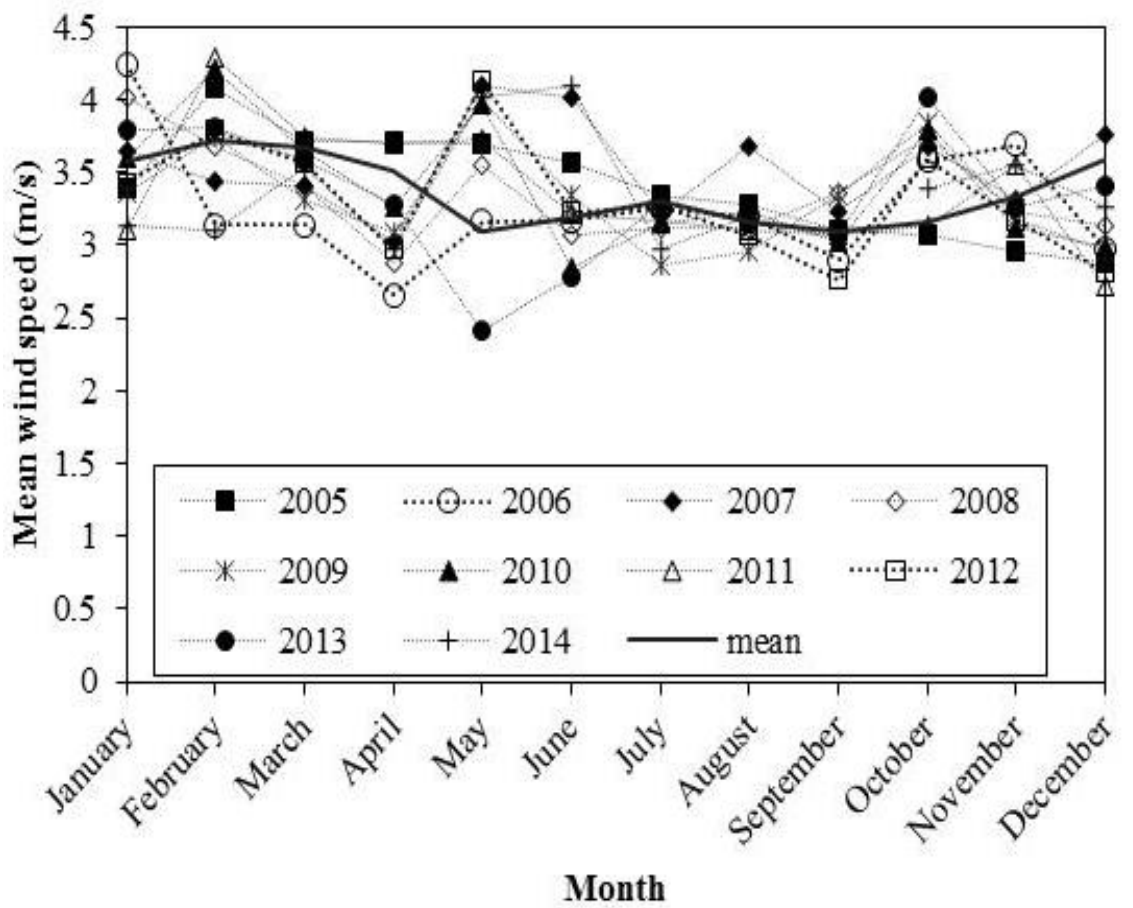

Figure 2. Monthly mean wind speed for the period of 2005-2014 in Sinop 


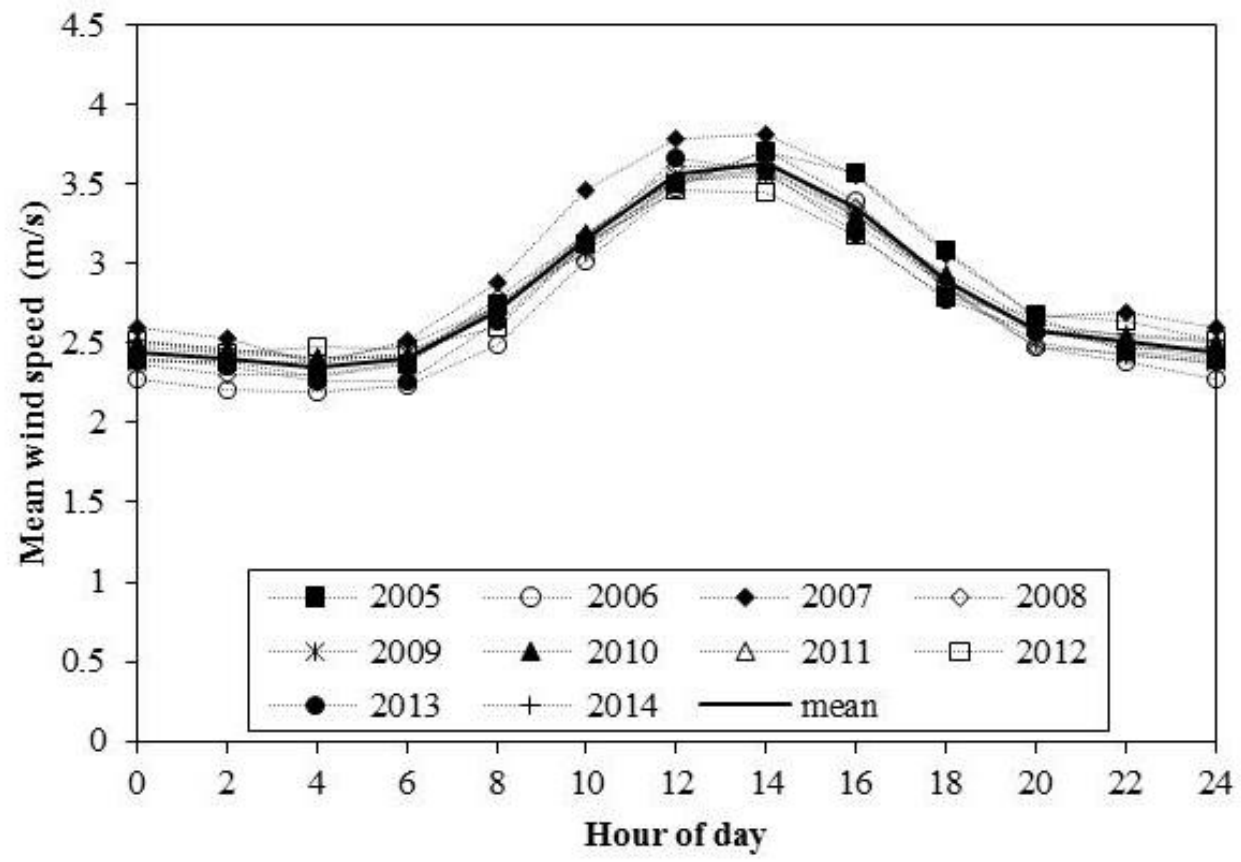

Figure 3. Diurnal variation of mean wind speed for the period of 2005-2014 in Sinop

The wind speed data in time-series format is usually arranged in the frequency distribution format since it is more convenient for statistical analysis. Therefore, the available time-series data were arranged as frequency distribution format for the period of 2005-2014 in Table 1. The wind speed is grouped into classes in the second column of Table 1. The mean wind speeds are calculated for each speed class intervals in the third column using the arithmetic mean. The fourth column shows the frequency of occurrence of each speed class. The probability density distributions calculated from the actual, Weibull and Rayleigh functions are presented in the fifth, sixth and seventh columns, respectively. It can be seen from Table 1 that the maximum probability density values are in the range of 12 and $2-3 \mathrm{~m} / \mathrm{s}$.

The yearly probability density and the cumulative distributions derived from the time-series data from Sinop are presented in Figures 4 and 5, respectively. The yearly probability density and the cumulative distributions are illustrated in Figure 6 for all the investigated years. All the curves show a similar trend for wind speeds' probability and cumulative distribution.

The monthly mean wind speed values and the standard deviations were calculated from Eqs. (1) and (2) using measured data. The monthly mean wind speed values $\left(v_{m}\right)$ and standard deviations $(\sigma)$ are given in Table 2 for Weibull distribution. Most of the monthly mean wind speed values are between 2.0 and $4.0 \mathrm{~m} / \mathrm{s}$. February of 2010 has the highest monthly mean wind speed value with $4.07 \mathrm{~m} / \mathrm{s}$, March of 2013 has the lowest monthly mean wind speed value with $2.39 \mathrm{~m} / \mathrm{s}$. Generally, it is determined that the highest mean wind speed values are in February and March, and the lowest mean wind speed values are in September and October. Having analyzed the 118 months of wind speed data, it can be concluded that the wind speed distribution differs remarkably from one month to the next. The monthly and yearly standard deviation values are mostly between 1.0 and $2.0 \mathrm{~m} / \mathrm{s}$. 
Journal of Thermal Engineering, Research Article, Vol. 5, No. 4, pp. 277-292, July, 2019

Table 1. The measured hourly time-series data in frequency distribution format for the period of 2005-2014 and the probability density distributions calculated from the Weibull, $\left(f_{W}(v j)\right)$, and Rayleigh $\left(f_{R}(v j)\right)$

\begin{tabular}{|l|l|l|l|l|l|l|}
\hline $\boldsymbol{j}$ & $\boldsymbol{v}_{\mathbf{j}}$ & $\boldsymbol{v}_{\boldsymbol{m} \cdot \boldsymbol{j}}$ & $\boldsymbol{f}_{\boldsymbol{j}}$ & $\boldsymbol{f}\left(\boldsymbol{v}_{j}\right)$ & $\boldsymbol{f}_{\boldsymbol{w}}\left(\boldsymbol{v}_{j}\right)$ & $\boldsymbol{f}_{\boldsymbol{R}}\left(\boldsymbol{v}_{j}\right)$ \\
\hline $\mathbf{1}$ & $0-1$ & 0.5 & 10262 & 0.120892 & 0.153598 & 0.155466 \\
\hline $\mathbf{2}$ & $1-2$ & 1.5 & 22848 & 0.274176 & 0.239059 & 0.24075 \\
\hline $\mathbf{3}$ & $2-3$ & 2.5 & 18635 & 0.222812 & 0.238165 & 0.236103 \\
\hline $\mathbf{4}$ & $3-4$ & 3.5 & 13138 & 0.158936 & 0.176315 & 0.174135 \\
$\mathbf{5}$ & $4-5$ & 4.5 & 8029 & 0.097479 & 0.101911 & 0.102129 \\
\hline $\mathbf{6}$ & $5-6$ & 5.5 & 4730 & 0.057069 & 0.047457 & 0.048914 \\
\hline $\mathbf{7}$ & $6-7$ & 6.5 & 2571 & 0.031054 & 0.018396 & 0.019433 \\
\hline $\mathbf{8}$ & $7-8$ & 7.5 & 1364 & 0.016134 & 0.006189 & 0.006472 \\
\hline $\mathbf{9}$ & $8-9$ & 8.5 & 810 & 0.009546 & 0.001906 & 0.001821 \\
\hline $\mathbf{1 0}$ & $9-10$ & 9.5 & 456 & 0.005325 & 0.000572 & 0.000435 \\
\hline $\mathbf{1 1}$ & $10-11$ & 10.5 & 279 & 0.003284 & 0.000177 & $8.89 \mathrm{E}-05$ \\
\hline $\mathbf{1 2}$ & $11-12$ & 11.5 & 153 & 0.001806 & $5.77 \mathrm{E}-05$ & $1.56 \mathrm{E}-05$ \\
\hline $\mathbf{1 3}$ & $12-13$ & 12.5 & & 0.000757 & $1.97 \mathrm{E}-05$ & $2.36 \mathrm{E}-06$ \\
$\mathbf{1 4}$ & $13-14$ & 13.5 & & 0.000437 & $6.76 \mathrm{E}-06$ & $3.08 \mathrm{E}-07$ \\
$\mathbf{1 5}$ & $14-15$ & 14.5 & 65 & 0.000117 & $2.25 \mathrm{E}-06$ & $6.23 \mathrm{E}-09$ \\
$\mathbf{1 6}$ & $15-16$ & 15.5 & 36 & $7.8 \mathrm{E}-05$ & $7.59 \mathrm{E}-07$ & $9.45 \mathrm{E}-11$ \\
$\mathbf{1 7}$ & $16-17$ & 16.5 & 10 & 0.000056 & $2.47 \mathrm{E}-07$ & $6.01 \mathrm{E}-12$ \\
$\mathbf{1 8}$ & $17-18$ & 17.5 & 7 & $2.24 \mathrm{E}-05$ & $7.71 \mathrm{E}-08$ & $3.23 \mathrm{E}-13$ \\
$\mathbf{1 9}$ & $18-19$ & 18.5 & 5 & $1.12 \mathrm{E}-05$ & $2.32 \mathrm{E}-08$ & $1.46 \mathrm{E}-14$ \\
$\mathbf{2 0}$ & $19-20$ & 19.5 & 2 & $1.12 \mathrm{E}-05$ & $6.75 \mathrm{E}-09$ & $3.97 \mathrm{E}-19$ \\
& & & 1 & & & \\
& & & 1 & & & \\
\hline
\end{tabular}

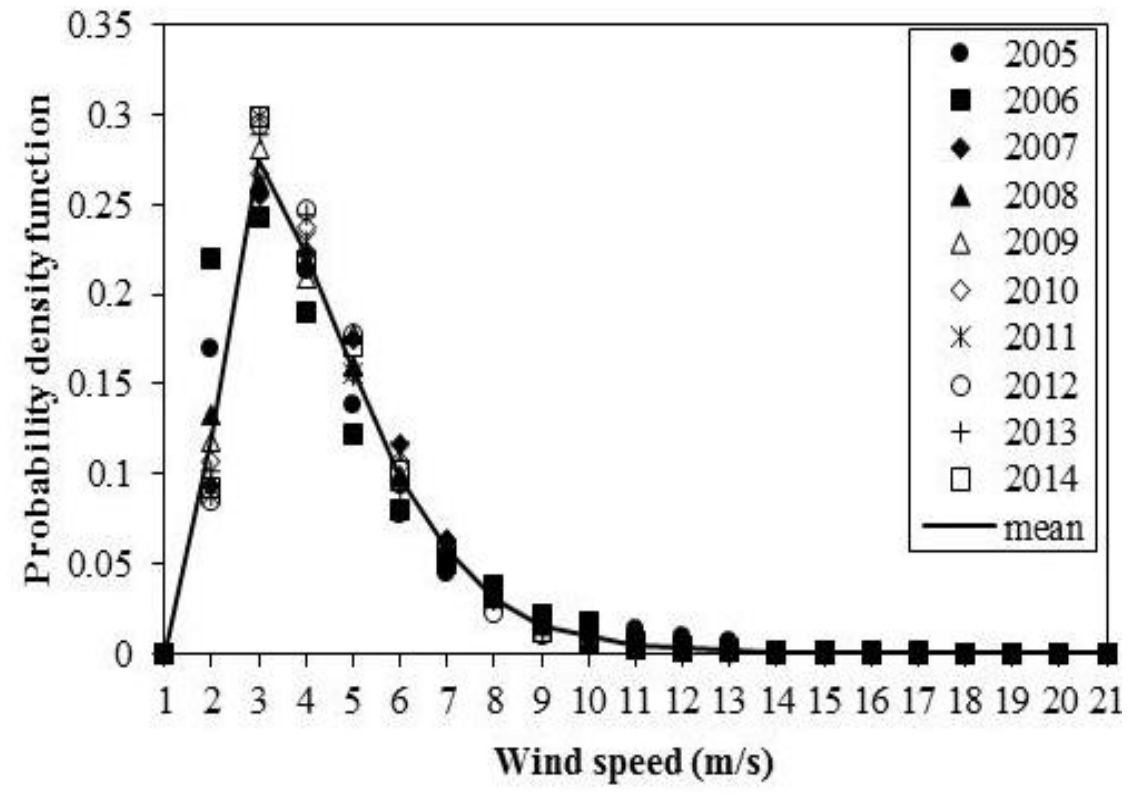

Figure 4. Yearly wind speed probability density distributions, derived from the measured. hourly time series 
Journal of Thermal Engineering, Research Article, Vol. 5, No. 4, pp. 277-292, July, 2019

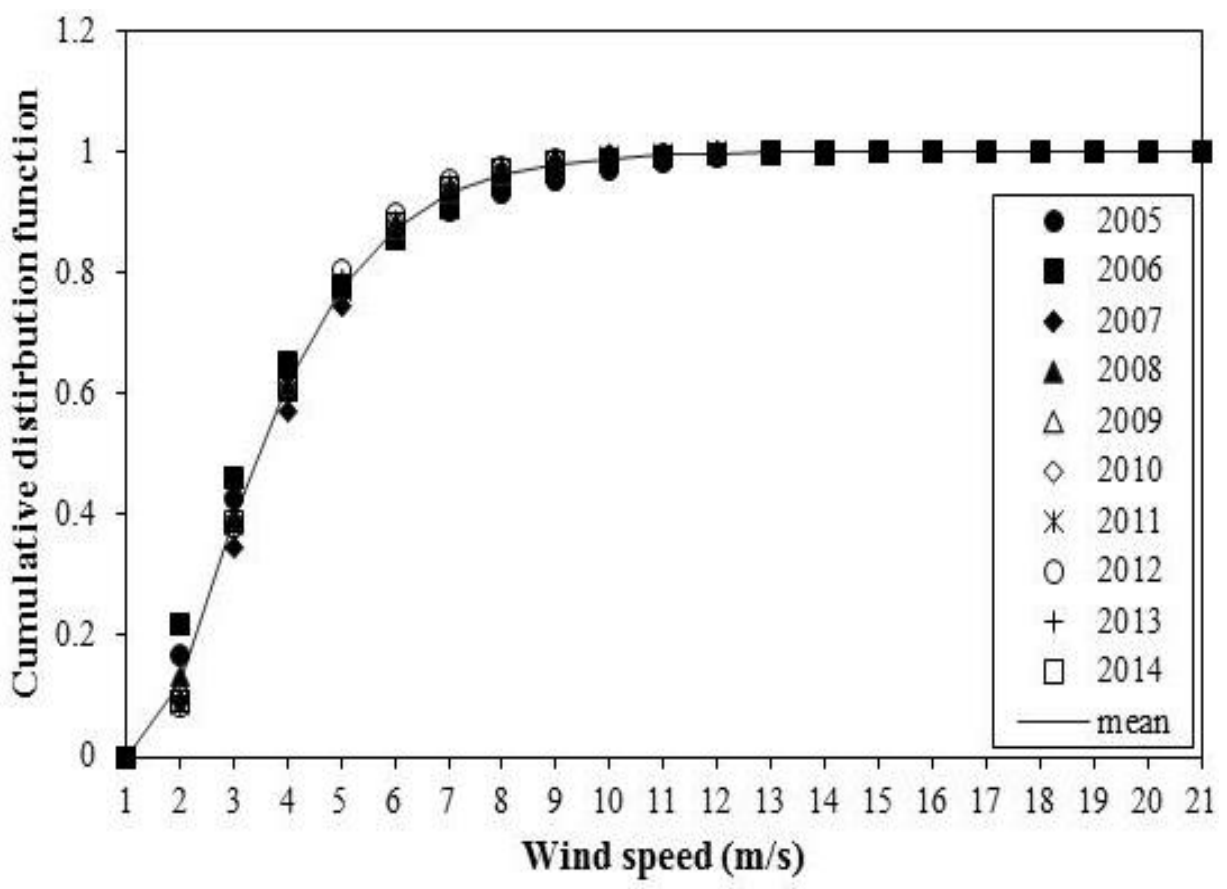

Figure 5. Yearly wind speed cumulative probability distributions, derived from the measured hourly time series

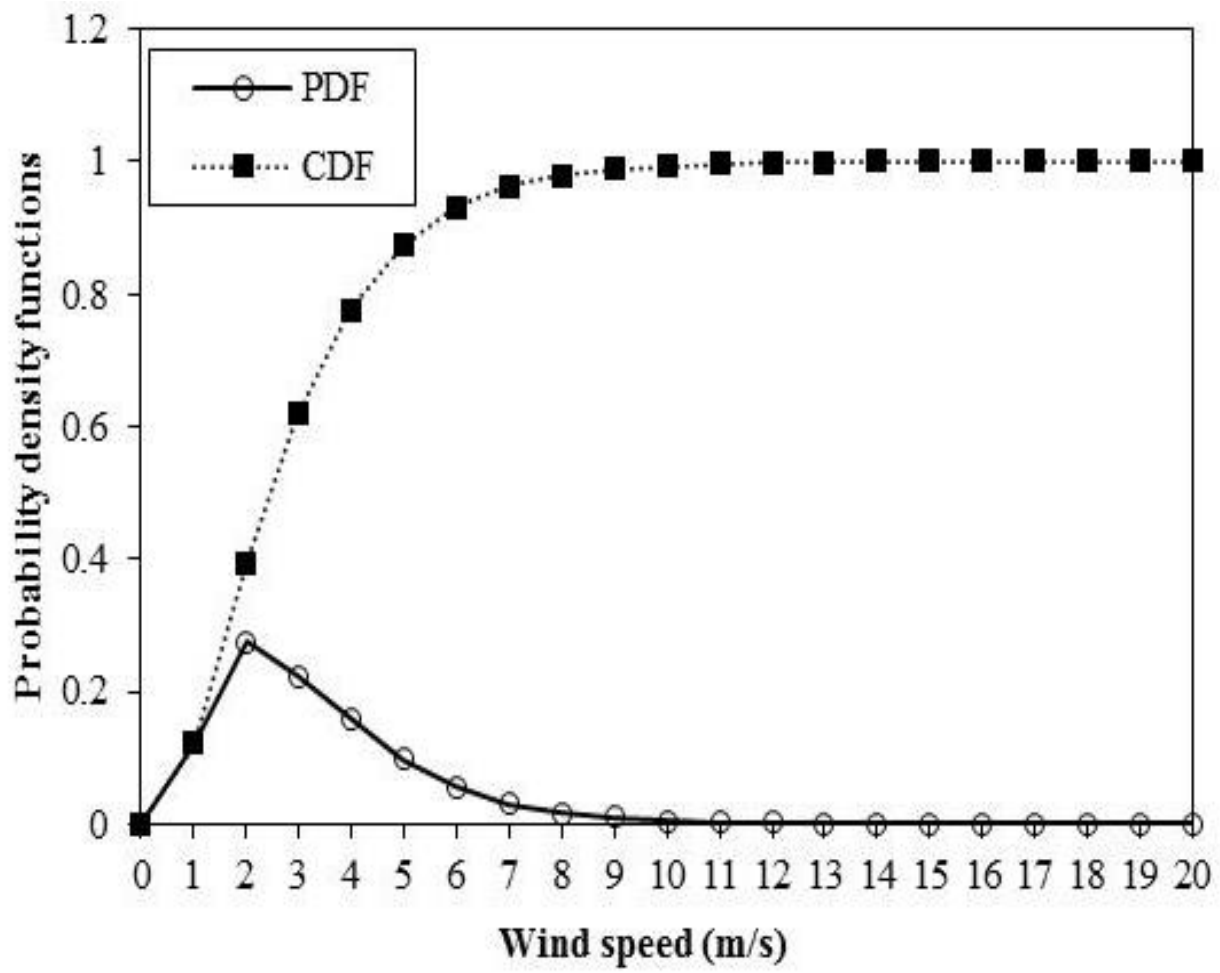

Figure 6. The wind speed probability density and cumulative probability distributions for whole years, derived from the measured hourly time-series 
Journal of Thermal Engineering, Research Article, Vol. 5, No. 4, pp. 277-292, July, 2019

Table 2. Monthly mean wind speed and standard deviations to Weibull distribution

\begin{tabular}{|c|c|c|c|c|c|c|c|c|c|c|c|}
\hline Month & Parameters & 2005 & 2006 & 2007 & 2008 & 2009 & 2010 & 2011 & 2012 & 2013 & 2014 \\
\hline \multirow[t]{2}{*}{ January } & $v_{m}$ & 2.67 & 3.61 & 3.10 & 3.43 & 2.97 & 3.27 & 2.68 & 3.09 & 3.19 & 2.83 \\
\hline & $\sigma$ & 1.49 & 2.19 & 1.42 & 2.04 & 1.50 & 1.59 & 1.32 & 1.38 & 1.03 & 1.55 \\
\hline \multirow[t]{2}{*}{ February } & $v_{m}$ & 3.21 & 2.47 & 3.22 & 3.25 & 3.61 & 4.07 & 3.82 & 3.29 & 3.78 & 2.71 \\
\hline & $\sigma$ & 1.67 & 1.91 & 1.59 & 1.66 & 1.63 & 1.92 & 2.01 & 1.62 & 1.79 & 1.18 \\
\hline \multirow[t]{2}{*}{ March } & $v_{m}$ & 3.01 & 2.88 & 3.73 & 3.26 & 3.97 & 3.54 & 3.25 & 3.63 & 2.39 & 3.90 \\
\hline & $\sigma$ & 1.58 & 1.20 & 1.91 & 1.43 & 1.96 & 1.92 & 1.71 & 1.71 & 1.08 & 1.71 \\
\hline \multirow[t]{2}{*}{ April } & $v_{m}$ & 3.18 & 2.99 & 3.38 & 3.30 & 3.06 & 3.59 & 3.61 & 3.36 & 3.42 & 3.41 \\
\hline & $\sigma$ & 1.64 & 1.85 & 1.62 & 1.45 & 1.60 & 1.97 & 1.55 & 1.45 & 1.70 & 1.43 \\
\hline \multirow[t]{2}{*}{ May } & $v_{m}$ & 2.71 & 2.51 & 3.04 & 3.16 & 3.11 & 2.93 & 2.74 & 2.53 & 2.86 & - \\
\hline & $\sigma$ & 1.47 & 1.34 & 1.43 & 1.49 & 1.36 & 1.38 & 1.07 & 1.04 & 1.26 & - \\
\hline \multirow[t]{2}{*}{ June } & $v_{m}$ & 2.89 & 2.90 & 3.54 & 3.05 & 2.89 & 3.09 & 2.92 & 2.94 & 2.92 & 3.02 \\
\hline & $\sigma$ & 1.78 & 2.00 & 1.73 & 1.56 & 1.40 & 1.50 & 1.28 & 1.30 & 1.29 & 1.41 \\
\hline \multirow[t]{2}{*}{ July } & $v_{m}$ & 2.58 & 3.47 & 3.15 & 3.11 & 2.91 & 2.78 & 3.59 & 2.87 & 3.01 & 3.47 \\
\hline & $\sigma$ & 1.33 & 3.00 & 1.46 & 1.66 & 1.51 & 1.35 & 1.73 & 1.34 & 1.61 & 1.63 \\
\hline \multirow[t]{2}{*}{ August } & $v_{m}$ & 3.10 & 2.93 & 3.11 & 2.96 & 2.75 & 3.00 & 2.98 & 3.02 & 3.02 & 2.71 \\
\hline & $\sigma$ & 2.09 & 1.57 & 1.55 & 1.63 & 1.43 & 1.64 & 1.46 & 1.46 & 1.55 & 1.32 \\
\hline \multirow[t]{2}{*}{ September } & $v_{m}$ & 2.81 & 2.61 & 3.57 & 2.91 & 2.46 & 2.65 & 2.63 & 2.69 & 3.03 & 2.86 \\
\hline & $\sigma$ & 1.74 & 1.91 & 2.19 & 1.71 & 1.16 & 1.15 & 1.29 & 1.30 & 1.34 & 1.39 \\
\hline \multirow[t]{2}{*}{ October } & $v_{m}$ & 3.09 & 2.43 & 2.81 & 2.46 & 2.77 & 2.79 & 3.47 & 2.84 & 2.87 & 2.52 \\
\hline & $\sigma$ & 1.83 & 1.54 & 1.41 & 1.45 & 1.45 & 1.25 & 1.75 & 1.30 & 1.55 & 1.07 \\
\hline \multirow[t]{2}{*}{ November } & $v_{m}$ & 3.22 & 2.46 & 3.53 & 2.62 & 2.94 & 2.58 & 2.66 & 2.74 & 2.61 & 3.20 \\
\hline & $\sigma$ & 2.02 & 1.80 & 1.67 & 1.60 & 1.67 & 1.19 & 1.37 & 1.27 & 1.20 & 1.85 \\
\hline \multirow[t]{2}{*}{ December } & $v_{m}$ & 2.54 & 2.29 & 3.41 & 3.49 & 3.60 & 3.40 & 2.76 & 3.35 & 3.08 & 3.14 \\
\hline & $\sigma$ & 1.44 & 2.09 & 1.88 & 1.88 & 1.76 & 1.71 & 1.25 & 1.44 & 1.71 & 1.61 \\
\hline
\end{tabular}

Table 3 shows the yearly values of the two Weibull parameters, the scale parameter $c(\mathrm{~m} / \mathrm{s})$ and the shape parameter $k$ (dimensionless), calculated from the long term wind data for Sinop. In addition, Table 3 shows monthly values of $k$ and $c$. The values of $c$ and $k$ were determined using the method described in Theory section. It is clear that the parameter $k$ has a much smaller, temporal variation than the parameter $c$. The $k$ value is between 1.09 (in December of 2006) and 3.42 (in January of 2013), while the $c$ value varies from 2.37 (in December of 2006) to 4.60 (in February of 2010) m/s. The mean values of parameters $k$ and $c$ were calculated as 2.02 and $3.43 \mathrm{~m} / \mathrm{s}$, respectively. The shape and scale parameters for May of 2014 could not be obtained for various reasons provided by the Turkish State Meteorological Service. The mean wind intensity and standard deviation values are important in predicting shape and scale parameters. 
Journal of Thermal Engineering, Research Article, Vol. 5, No. 4, pp. 277-292, July, 2019

Table 3. Monthly shape parameter $(k)$ and scale parameter $(c)$ values according to the Weibull distribution for period of 2005-2014

\begin{tabular}{|c|c|c|c|c|c|c|c|c|c|c|c|}
\hline Month & Parameters & 2005 & 2006 & 2007 & 2008 & 2009 & 2010 & 2011 & 2012 & 2013 & 2014 \\
\hline \multirow[t]{2}{*}{ January } & $\mathbf{k}$ & 1.85 & 1.69 & 2.31 & 1.72 & 2.06 & 2.17 & 2.12 & 2.39 & 3.42 & 1.90 \\
\hline & c & 3.01 & 4.04 & 3.50 & 3.84 & 3.35 & 3.70 & 3.03 & 3.49 & 3.55 & 3.19 \\
\hline \multirow[t]{2}{*}{ February } & $\mathbf{k}$ & 2.01 & 1.30 & 2.12 & 2.05 & 2.35 & 2.23 & 1.97 & 2.13 & 2.22 & 2.44 \\
\hline & $\mathbf{c}$ & 3.62 & 2.68 & 3.64 & 3.67 & 4.08 & 4.60 & 4.31 & 3.72 & 4.27 & 3.05 \\
\hline \multirow[t]{2}{*}{ March } & $\mathbf{k}$ & 1.98 & 2.57 & 2.03 & 2.42 & 2.13 & 1.91 & 1.98 & 2.24 & 2.34 & 2.43 \\
\hline & c & 3.39 & 3.24 & 4.21 & 3.68 & 4.48 & 3.99 & 3.66 & 4.10 & 2.69 & 4.39 \\
\hline \multirow[t]{2}{*}{ April } & $\mathbf{k}$ & 2.02 & 1.66 & 2.20 & 2.42 & 1.99 & 1.89 & 2.48 & 2.47 & 2.10 & 2.55 \\
\hline & c & 3.59 & 3.35 & 3.82 & 3.72 & 3.45 & 4.05 & 4.07 & 3.79 & 3.86 & 3.84 \\
\hline \multirow[t]{2}{*}{ May } & $\mathbf{k}$ & 1.92 & 1.94 & 2.24 & 2.24 & 2.43 & 2.23 & 2.75 & 2.59 & 2.41 & - \\
\hline & $\mathbf{c}$ & 3.06 & 2.83 & 3.43 & 3.57 & 3.51 & 3.30 & 3.08 & 2.85 & 3.23 & - \\
\hline \multirow[t]{2}{*}{ June } & $\mathbf{k}$ & 1.67 & 1.47 & 2.15 & 2.04 & 2.16 & 2.16 & 2.42 & 2.41 & 2.40 & 2.25 \\
\hline & $\mathbf{c}$ & 3.24 & 3.20 & 4.00 & 3.45 & 3.26 & 3.48 & 3.30 & 3.32 & 3.29 & 3.40 \\
\hline \multirow[t]{2}{*}{ July } & $\mathbf{k}$ & 2.02 & 1.15 & 2.28 & 1.95 & 2.00 & 2.17 & 2.18 & 2.27 & 1.94 & 2.24 \\
\hline & $\mathbf{c}$ & 2.91 & 3.65 & 3.56 & 3.51 & 3.28 & 3.14 & 4.06 & 3.24 & 3.39 & 3.92 \\
\hline \multirow{2}{*}{ August } & $\mathbf{k}$ & 1.50 & 1.94 & 2.10 & 1.89 & 2.00 & 1.89 & 2.15 & 2.16 & 2.03 & 2.16 \\
\hline & $\mathbf{c}$ & 3.43 & 3.30 & 3.51 & 3.34 & 3.10 & 3.38 & 3.37 & 3.41 & 3.41 & 3.07 \\
\hline \multirow[t]{2}{*}{ September } & $\mathbf{k}$ & 1.65 & 1.38 & 1.67 & 1.75 & 2.24 & 2.46 & 2.13 & 2.16 & 2.40 & 2.16 \\
\hline & $\mathbf{c}$ & 3.14 & 2.86 & 4.00 & 3.27 & 2.78 & 2.99 & 2.97 & 3.03 & 3.41 & 3.23 \\
\hline \multirow[t]{2}{*}{ October } & $\mathbf{k}$ & 1.73 & 1.61 & 2.09 & 1.73 & 1.99 & 2.36 & 2.07 & 2.30 & 1.91 & 2.50 \\
\hline & $\mathbf{c}$ & 3.47 & 2.72 & 3.17 & 2.76 & 3.12 & 3.14 & 3.92 & 3.21 & 3.23 & 2.84 \\
\hline \multirow[t]{2}{*}{ November } & $\mathbf{k}$ & 1.63 & 1.38 & 2.22 & 1.68 & 1.81 & 2.29 & 2.03 & 2.28 & 2.30 & 1.78 \\
\hline & $\mathbf{c}$ & 3.60 & 2.70 & 3.98 & 2.94 & 3.30 & 2.91 & 3.01 & 3.09 & 2.95 & 3.60 \\
\hline \multirow[t]{2}{*}{ December } & $\mathbf{k}$ & 1.83 & 1.09 & 1.88 & 1.93 & 2.15 & 2.07 & 2.34 & 2.49 & 1.87 & 2.03 \\
\hline & c & 2.86 & 2.37 & 3.84 & 3.94 & 4.07 & 3.83 & 3.11 & 3.78 & 3.47 & 3.54 \\
\hline
\end{tabular}

The Weibull and Rayleigh approximations of the actual probability distribution of wind speeds are shown in Fig. 7, while a comparison of the two approximations is given in Table 4. In Fig. 7, the probability distribution of the actual data, the Weibull probability distribution, and the Rayleigh probability distribution are plotted versus the wind speed according to the average of ten years data. The probability ratio of the Weibull distribution is higher than the Rayleigh distribution. It can be seen from Fig. 7 that the Weibull distribution fit to the actual distribution data is closer than the Rayleigh distribution.

Table 4. $\mathrm{R}^{2}$, RMSE and $\chi^{2}$ values obtained from Weibull and Rayleigh distributions

\begin{tabular}{|l|l|l|l|l|l|l|}
\hline Years & \multicolumn{3}{|c|}{ Weibull Distribution } & \multicolumn{3}{c|}{ Rayleigh Distribution } \\
\hline & $\mathbf{R}^{\mathbf{2}}$ & RMSE & $\boldsymbol{\chi}^{\mathbf{2}}$ & $\mathbf{R}^{\mathbf{2}}$ & RMSE & $\chi^{\mathbf{2}}$ \\
\hline $\mathbf{2 0 0 5}$ & 0.982 & 0.000060 & 0.000140 & 0.969 & 0.000107 & 0.000231 \\
\hline $\mathbf{2 0 0 6}$ & 0.994 & 0.000016 & 0.000036 & 0.930 & 0.000209 & 0.000439 \\
\hline $\mathbf{2 0 0 7}$ & 0.969 & 0.000110 & 0.000256 & 0.966 & 0.000120 & 0.000257 \\
\hline $\mathbf{2 0 0 8}$ & 0.969 & 0.000066 & 0.000155 & 0.981 & 0.000069 & 0.000149 \\
\hline $\mathbf{2 0 0 9}$ & 0.962 & 0.000146 & 0.000340 & 0.962 & 0.000147 & 0.000316 \\
\hline $\mathbf{2 0 1 0}$ & 0.966 & 0.000128 & 0.000298 & 0.965 & 0.000135 & 0.000290 \\
\hline $\mathbf{2 0 1 1}$ & 0.937 & 0.000258 & 0.000597 & 0.931 & 0.000284 & 0.000608 \\
\hline $\mathbf{2 0 1 2}$ & 0.957 & 0.000191 & 0.000446 & 0.937 & 0.000284 & 0.000612 \\
\hline $\mathbf{2 0 1 3}$ & 0.961 & 0.000140 & 0.000314 & 0.955 & 0.000164 & 0.000345 \\
\hline $\mathbf{2 0 1 4}$ & 0.941 & 0.000237 & 0.000547 & 0.936 & 0.000258 & 0.000552 \\
\hline
\end{tabular}




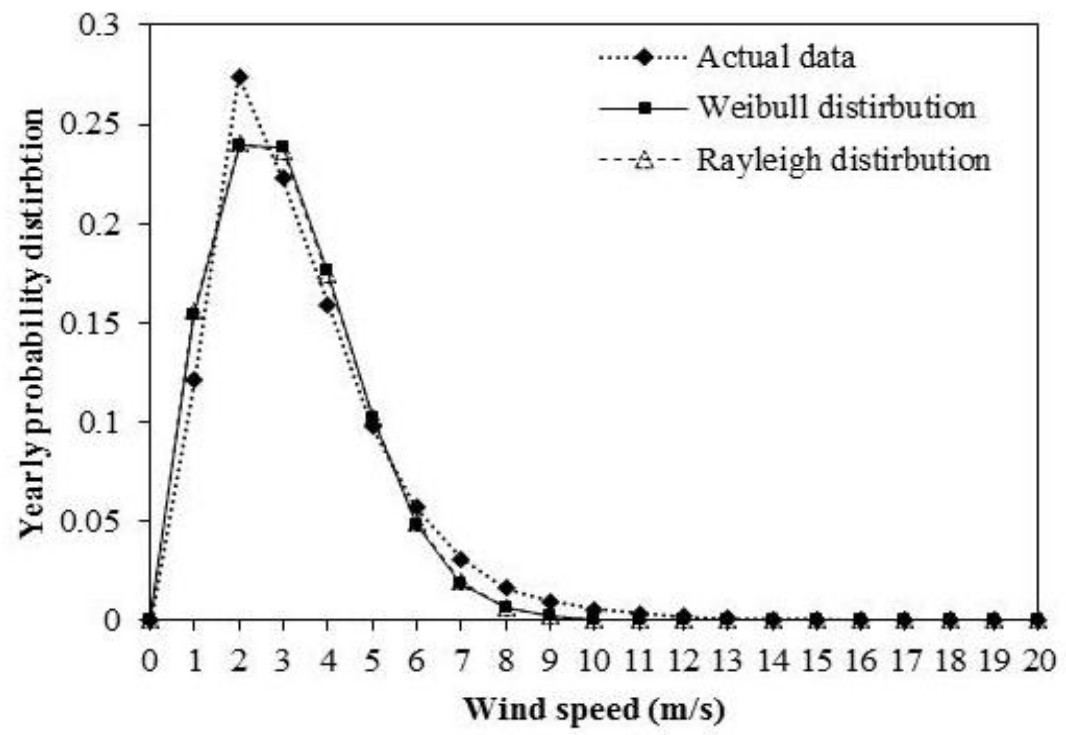

Figure 7. The comparison of Weibull and Rayleigh approximations with the actual probability distribution of wind speeds

The values of the statistical parameters $\left(R^{2}, R M S E\right.$, and $\left.\chi^{2}\right)$ obtained from the Weibull and Rayleigh distributions are given in Table 4. The $R^{2}$ value was found to be between 0.937-0.994 in the Weibull distribution and $0.930-0.981$ in the Rayleigh distribution. The RMSE and $\chi^{2}$ values range from $1.6 \times 10^{-6}$ to $2.58 \times 10^{-5}$ and $3.6 \times 10^{-6}$ to $5.97 \times 10^{-5}$ for the Weibull distribution, while they vary between $6.9 \times 10^{-6}-2.84 \times 10^{-5}$ and $1.49 \times 10^{-5}-6.12 \times 10^{-5}$ for the Rayleigh distributions, respectively. As can be seen in Table 4, the highest $R^{2}$ value was obtained by using the Weibull distribution. However, the results have shown that the RMSE and $\chi^{2}$ values of the Weibull distribution were lower than the values obtained for the Rayleigh distribution. As a result, the Weibull approximation was found to be the most accurate distribution according to the highest value of $R^{2}$ and the lowest values of RMSE and $\chi^{2}$.

Fig. 8 shows the monthly change in the $R^{2}$ obtained from the Weibull and Rayleigh distributions for Sinop using the ten-year data. The range of $R^{2}$ values change from 0.89 to 0.95 in the Weibull distribution and 0.81 to 0.92 in the Rayleigh distribution. Because the $R^{2}$ value is closer to 1 in the Weibull distribution, it is understood that the Weibull distribution is more suitable for modeling the wind data for Sinop.

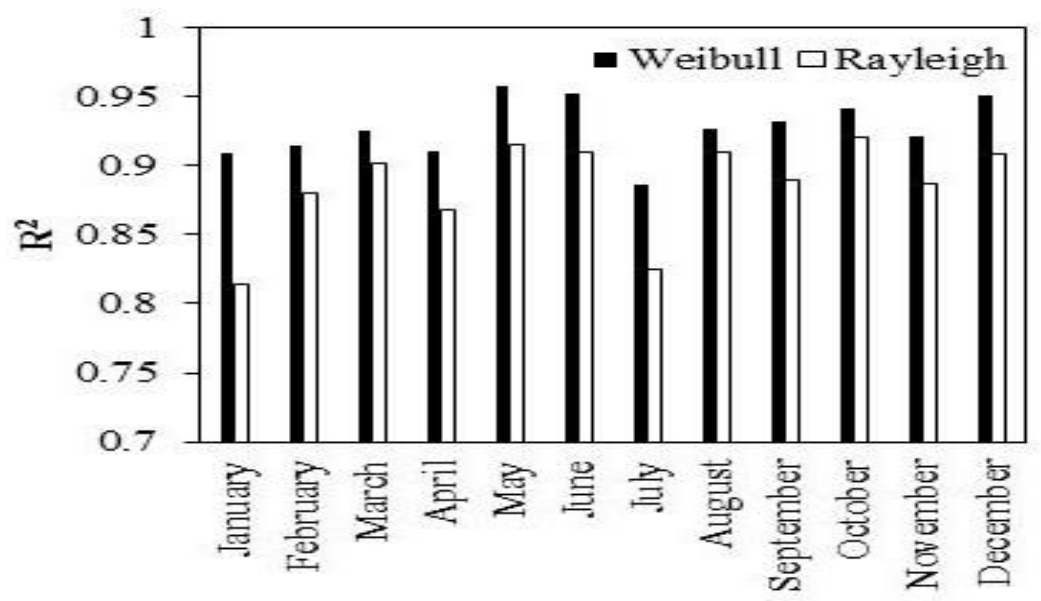

Month

Figure 8. The change of $\mathrm{R}^{2}$ values obtained from Weibull and Rayleigh distribution to months 
The Weibull distribution parameters and the Rayleigh distribution parameters are given in Table 5 and Table 6 according to the investigated years, respectively. The maximum mean velocity $\left(V_{\max }\right)$ in the Weibull distribution ranged from 4.48 to $5.46 \mathrm{~m} / \mathrm{s}$ and the mean power density $\left(P_{\mathrm{w}}\right)$ ranged from 28.29 to $39.20 \mathrm{~W} / \mathrm{m}^{2}$. In the Rayleigh distribution, $V_{\max }$ varied from 4.39 to $5.25 \mathrm{~m} / \mathrm{s}$ and $P_{R}$ varied from 24.27 to $41.65 \mathrm{~W} / \mathrm{m}^{2}$.

Table 5. Weibull distribution parameters

\begin{tabular}{|c|c|c|c|c|c|c|c|}
\hline Year & $\mathbf{k}$ & $\begin{array}{c}\mathbf{c} \\
(\mathbf{m} / \mathbf{s})\end{array}$ & $\begin{array}{c}\mathbf{V}_{\mathbf{m}} \\
(\mathbf{m} / \mathbf{s})\end{array}$ & $\begin{array}{c}\boldsymbol{\sigma} \\
(\mathbf{m} / \mathbf{s})\end{array}$ & $\mathbf{V}_{\mathbf{m o d}}(\mathbf{m} / \mathbf{s})$ & $\begin{array}{c}\mathbf{V}_{\mathbf{m a x E}} \\
(\mathbf{m} / \mathbf{s})\end{array}$ & $\begin{array}{c}\mathbf{P w}_{\mathbf{w}} \\
\left(\mathbf{W} / \mathbf{m}^{2}\right)\end{array}$ \\
\hline $\mathbf{2 0 0 5}$ & 1.79 & 3.29 & 2.93 & 1.69 & 2.08 & 5.00 & 33.04 \\
\hline $\mathbf{2 0 0 6}$ & 1.52 & 3.15 & 2.84 & 1.90 & 1.57 & 5.09 & 37.21 \\
\hline $\mathbf{2 0 0 7}$ & 2.09 & 3.69 & 3.27 & 1.64 & 2.71 & 5.46 & 39.20 \\
\hline $\mathbf{2 0 0 8}$ & 1.94 & 3.49 & 3.10 & 1.66 & 2.41 & 5.02 & 35.74 \\
\hline $\mathbf{2 0 0 9}$ & 2.02 & 3.48 & 3.08 & 1.59 & 2.49 & 4.88 & 33.85 \\
\hline $\mathbf{2 0 1 0}$ & 2.07 & 3.51 & 3.11 & 1.57 & 2.56 & 4.86 & 33.97 \\
\hline $\mathbf{2 0 1 1}$ & 2.15 & 3.46 & 3.06 & 1.50 & 2.58 & 4.69 & 31.30 \\
\hline $\mathbf{2 0 1 2}$ & 2.28 & 3.40 & 3.01 & 1.39 & 2.64 & 4.48 & 28.29 \\
\hline $\mathbf{2 0 1 3}$ & 2.16 & 3.38 & 2.99 & 1.45 & 2.54 & 4.57 & 29.04 \\
\hline $\mathbf{2 0 1 4}$ & 2.13 & 3.46 & 2.06 & 1.50 & 2.57 & 4.71 & 31.48 \\
\hline
\end{tabular}

Table 6. Rayleigh distribution parameters

\begin{tabular}{|c|c|c|c|c|c|c|}
\hline Year & $\mathbf{c}(\mathbf{m} / \mathbf{s})$ & $\mathbf{V}_{\mathbf{m}}(\mathbf{m} / \mathbf{s})$ & $\boldsymbol{\sigma}(\mathbf{m} / \mathbf{s})$ & $\mathbf{V}_{\mathbf{m o d}}(\mathbf{m} / \mathbf{s})$ & $\begin{array}{c}\mathbf{V}_{\mathbf{m a x E}} \\
(\mathbf{m} / \mathbf{s})\end{array}$ & $\mathbf{P}_{\mathbf{R}}\left(\mathbf{W} / \mathbf{m}^{2}\right)$ \\
\hline $\mathbf{2 0 0 5}$ & 3.25 & 2.88 & 1.50 & 2.29 & 4.59 & 27.89 \\
\hline $\mathbf{2 0 0 6}$ & 3.10 & 2.75 & 1.43 & 2.19 & 4.39 & 24.27 \\
\hline $\mathbf{2 0 0 7}$ & 3.71 & 3.29 & 1.72 & 2.62 & 5.25 & 41.65 \\
\hline $\mathbf{2 0 0 8}$ & 3.49 & 3.09 & 1.61 & 2.46 & 4.93 & 34.47 \\
\hline $\mathbf{2 0 0 9}$ & 3.49 & 3.09 & 1.61 & 2.46 & 4.93 & 34.48 \\
\hline $\mathbf{2 0 1 0}$ & 3.53 & 3.13 & 1.63 & 2.50 & 5.00 & 35.89 \\
\hline $\mathbf{2 0 1 1}$ & 3.49 & 3.10 & 1.62 & 2.47 & 4.94 & 34.75 \\
\hline $\mathbf{2 0 1 2}$ & 3.46 & 3.07 & 1.60 & 2.45 & 4.90 & 33.79 \\
\hline $\mathbf{2 0 1 3}$ & 3.42 & 3.03 & 1.58 & 2.42 & 4.84 & 32.64 \\
\hline $\mathbf{2 0 1 4}$ & 3.49 & 3.09 & 1.61 & 2.46 & 4.93 & 34.54 \\
\hline
\end{tabular}

The variation of mean wind speed with Weibull power density and Rayleigh power density are shown in Fig. 9 and in Fig. 10 with respect to the investigated years, respectively. The mean wind velocity was determined to be $2.95 \mathrm{~m} / \mathrm{s}$ for the Weibull distribution and $3.05 \mathrm{~m} / \mathrm{s}$ for the Rayleigh distribution. In the Weibull distribution, the highest power density was $39.20 \mathrm{~W} / \mathrm{m}^{2}$ in 2007 , the lowest power density was $28.30 \mathrm{~W} / \mathrm{m}^{2}$ in 2012 , and the mean power density was $33.31 \mathrm{~W} / \mathrm{m}^{2}$. In the Rayleigh distribution, the highest and the lowest power densities were determined to be $41.66 \mathrm{~W} / \mathrm{m}^{2}$ in 2007 and $24.27 \mathrm{~W} / \mathrm{m}^{2}$ in 2006 , respectively, and the obtained mean power density was $33.44 \mathrm{~W} / \mathrm{m}^{2}$. 


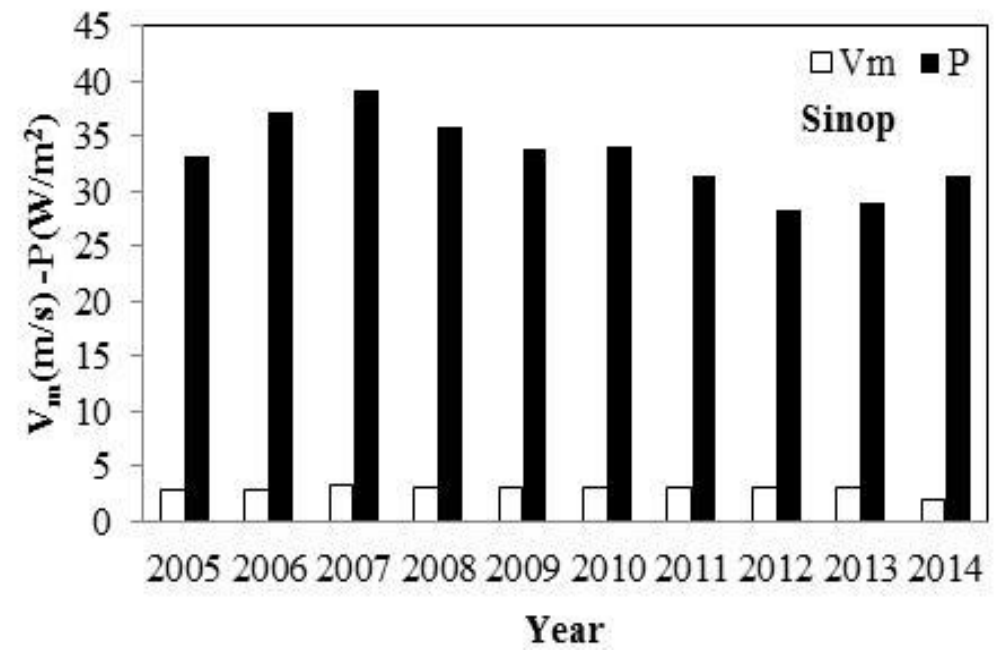

Figure 9. Yearly mean power density and wind speed according to Weibull distribution

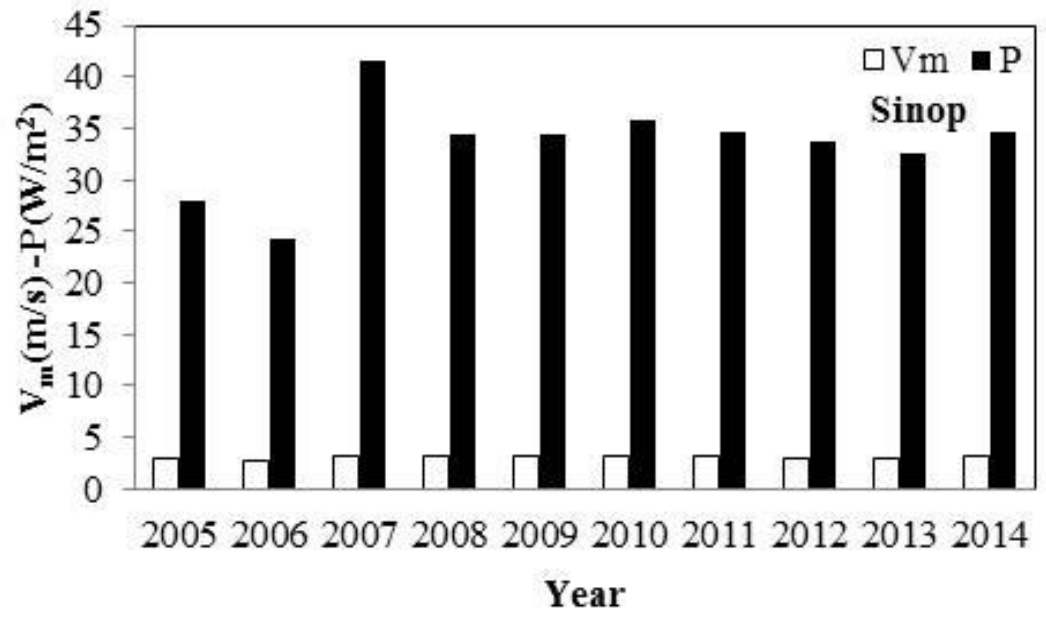

Figure 10. Yearly mean power density and wind speed according to Rayleigh distribution

\section{CONCLUSION}

In this study, the wind power density and wind speed distribution parameters of Sinop were statistically analyzed during the years of 2005-2014. Two probability density functions were fitted to the measured probability distributions on a yearly and monthly basis. Performances of the probability models were compared to the measured monthly and yearly wind speed values. Weibull and Rayleigh distributions were used for modeling and the success of this modeling process was evaluated according to $\mathrm{R}^{2}$, RMSE and $\chi^{2}$ parameters. The results can be summarized as follows:

- The mean wind speed was found as $3.36 \mathrm{~m} / \mathrm{s}$ for all years between 2004 and 2015 .

- The mean power densities were calculated as 33.31 and $33.44 \mathrm{~W} / \mathrm{m}^{2}$, respectively, for Weibull and Rayleigh distribution for the whole year.

- The Weibull model is generally better in fitting the measured yearly probability density distributions than the Rayleigh model, to the statistical criteria such as $\mathrm{R}^{2}$, RMSE and $\chi^{2}$. Therefore, it was concluded that it would be more appropriate to use the Weibull distribution for the analysis of Sinop's wind data. 
Journal of Thermal Engineering, Research Article, Vol. 5, No. 4, pp. 277-292, July, 2019

- The values of the shape parameter (k) and scale parameter (c) at Sinop were examined. The yearly mean values of $k$ and $c$ for thevWeibull distribution were determined to be 2.02 and $3.44 \mathrm{~m} / \mathrm{s}$ over the 10 year period of 2005-2014. The yearly mean $c$ value for the Rayleigh distribution was found to be $3.45 \mathrm{~m} / \mathrm{s}$. The Weibull shape parameter follows very closer to the Raleigh function, $\mathrm{k}=2$, for Sinop which means that the characteristics for the wind wave are regular and uniform.

- As a result, monthly average power and annual average power densities in Sinop are as small as $100 \mathrm{~W} / \mathrm{m}^{2}$. Therefore, it is not possible to support the network directly by wind energy systems; however it can be used in applications where there is no network access or in rural areas where low-power density is required. It has been decided that electricity generation from wind energy is suitable because the average speed on a daily and monthly basis usually is $3 \mathrm{~m} / \mathrm{s}$.

\section{REFERENCES}

[1] Pishgar-Komleh, S.H., Keyhani, A., Sefeedpari, P. (2015). Wind speed and power density analysis based on Weibull and Rayleigh distributions (a case study: Firouzkooh county of Iran). Renewable and Sustainable Energy Reviews, 42, 313-322.

[2] Sohoni, V., Gupta, S., Nema, R. (2016). A comparative analysis of wind speed probability distributions for wind power assessment of four sites. Turk J Elec Eng \& Comp Sci, 24, 4724-4735.

[3] Morgan, V.T. (1995). Statistical distributions of wind parameters at Sydney, Australia. Renew Energy, 6, 39-47.

[4] Seguro, J.V., Lambert, T.W. (2000). Modern estimation of the parameters of the Weibull wind speed distribution for wind energy analysis. J Wind Eng Ind Aerod, 85, 75-84.

[5] Costa Rocha, P.A., De Sousa, R.C., De Andrade, C.F., Da Silva, M.E.V. (2012). Comparison of seven numerical methods for determining Weibull parameters for wind energy generation in the northeast region of Brazil. Appl Energ, 89, 395-400.

[6] Ulgen, K., Hepbasli, A. (2002). Determination of Weibull parameters for wind energy analysis of Izmir, Turkey. Int J Energy Res, 26, 494-506.

[7] Celik, A.N. (2003). A statistical analysis of wind power density based on the Weibull and Rayleigh models at the southern region of Turkey. Renewable Energy, 29(4), 593-604.

[8] Karsli, V.M., Gecit, C. (2003). An investigation on wind power potential of Nurdag1- Gaziantep, Turkey. Renew Energy, 28, 823-830.

[9] Kose, R., Ozgur, M. A., Erbas, O., Tugcu, A. (2004). The analysis of wind data and energy potential in Kutahya, Turkey. Renew Sustain Energy Rev, 8, 277-288.

[10] Akpinar, E.K., Akpinar, S. (2004). Determination of the wind energy potential for Maden-Elazığ, Turkey. Energy Conversion and Management, 45, 2901-2914.

[11] Akpinar, E.K., Akpinar, S. (2004). Statistical Analysis of wind energy potential on the basis of the Weibull and Rayleigh distribution for Ağın-Elazı ̆̆, Turkey. J.Power Energy, 218, 557-565.

[12] Genc, A., Erisoglu, M., Pekgor, A., Oturanc, G., Hepbasli, A., Ulgen, K. (2005). Estimation of wind power potential using Weibull distribution. Energ Source, 27, 809-822.

[13] Akpinar, E.K. (2006). A statistical investigation of wind energy potential. Energy Sources, Part A, 28, 807-820.

[14] Gökcek, M., Bayülken, A., Bekdemir, Ş. (2007). Investigation of wind characteristics and wind energy potential in Kirklareli, Turkey. Renewable Energy, 32, 1739-1752.

[15] Yilmaz, V., Çelik, H.E. (2008). A statistical approach to estimate the wind speed distribution: the case of Gelibolu region. Doğuş Üniversitesi Dergisi, 9 (1), 122-132.

[16] Akdag, S.A., Güler, Ö. (2009). Calculation of wind energy potential and economic analysis by using Weibull Distribution-A case study from Turkey. Part 1: Determination of Weibull parameters. Energy Sources, Part B, 4, 18.

[17] Bilgili, M. and Şahin, B. (2009). Investigation of wind energy density in the Southern and Southwestern region of Turkey. Journal of Energy Engineering, 135, 1(12), 12-20.

[18] Mert, I., Karakus, C. (2015). A statistical analysis of wind speed data using Burr, generalized gamma, and Weibull distributions in Antakya, Turkey. Turk J Elec Eng \& Comp Sci, 23, 1571 -1586.

[19] Dokur, E., Kurban, M. (2015). Wind speed potential analysis based on Weibull distribution. Balkan Journal of Electrical \& Computer Engineering, 3(4), 231-235.

[20] Kaplan, Y.A., Aladağ, C. (2016). Comparison of different methods in estimating Weibull distribution parameters for wind power application. International Journal of Innovative Research in Science, Engineering and Technology. $5(12), 232-242$. 
Journal of Thermal Engineering, Research Article, Vol. 5, No. 4, pp. 277-292, July, 2019

[21] Yanıktepe, B., Özalp, C., Kaşka, Ö., Köroğlu T. (2011). An assessment of wind power potential in Osmaniye, Turkey. 6th International Advanced Technologies Symposium (IATS'11), 16-18 May 2011, Elazı̆̆, Turkey, 82-88.

[22] https://tr.depositphotos.com/vector-images/marmara.html?qview=53816051. 